\title{
The Reliability of Small World Network
}

\author{
${ }^{2}$ Noussaima El. Khattabi, ${ }^{1}$ Fouad Yakoubi and ${ }^{1}$ Mohamed El. Marraki \\ ${ }^{1}$ LRIT Associated Unit the CNRST (URAC29), \\ ${ }^{2}$ Laboratory of Conception and Systems, Faculty of Sciences, Mohammed V University, \\ P.O. Box 1014 RP, Agdal, Rabat, Morocco
}

\begin{abstract}
The asymptotic spanning tree entropy is a natural measure related to topological and dynamic properties of networks, namely their reliability. However, computing the number of spanning trees of networks using classical algebraic methods is very demanding tasks on term computational resources and time, especially for large networks such as complex networks. In this study, we give an analytic formula for the number of spanning trees and the asymptotic entropy of two type of small-world networks $G_{k}$ and $C_{k}$ by using two methods of decomposition based on geometrical transformation which are Bipartite method and Reduction method. Then, we estimate and compare the robustness level of the networks $G_{k}$ and $C_{k}$ that have the same average degree of nodes.
\end{abstract}

Key words: Number of spanning trees, asymptotic entropy, network reliability, complex network, small world network, bipartite method, reduction method

\section{INTRODUCTION}

In real life, often complex systems can be modeled by networks, the nodes represent the components of the system and links symbolize their interaction. For example, social networks, airline networks, biological networks and so on (Zhang, 2015; Reggiani et al., 2010; Javari et al., 2016). The complex systems characterized by their structural properties such as degree correlation, average distance, clustering coefficient,network synchronization, number of spanning trees and other characteristics (Newman et al., 2006; Cancho et al., 2001; Newman, 2003; Nishikawa and Motter, 2006). Many researches have proven rigorously relations between topological and dynamical properties of network. Then, knowing the topological properties of network, we expect accurately its behavior and its dynamical characteristics. In graph theory, the asymptotic spanning tree entropy present a powerful tools to interpret and analyze the relationship between structural proprieties and reliability of networks. The robustness and reliability is the ability of a network to continue performing well when it is subject to failures (Wang et al., 2006; Myrvold et al., 1991; Colbourn, 1987). The asymptotic spanning tree entropy is very useful to measure the level of reliability and robustness of networks.
In this study, we use the spanning trees entropy to estimate and compare the robustness of two kind of small-world networks $G_{k}$ and $C_{k}$. The entropy of $G_{n}{ }^{k}$ denoted by $\rho\left(G_{k}\right)$ defined (Lyons, 2005) as the limiting value:

$$
\rho\left(G_{k}\right)=\lim _{\left|V\left(G_{k}\right) \rightarrow+\infty\right|} \frac{\log \tau\left(G_{k}\right)}{\left|V_{\left(G_{k}\right)}\right|}
$$

First, we compute the number of spanning trees or what called the complexity $\rho\left(G_{k}\right)$. The best known method that computes the number of spanning trees of a graph $\mathrm{G}$ is the matrix-tree theorem (Kirkoff, 1847). However, computing the number of spanning trees using this method having high complexity $\Theta\left(n^{3}\right)$ is a demanding and difficult task namely for large graphs such as complex network "Small world network". For this reason, there has been much interest to find alternative methods to avoid the tedious calculations by giving explicit expressions for the number of spanning trees for some networks families such as Sierpinski gaskets grids and lattices (Wu, 1977; Nikolopoulos and Papadopoulos, 2004; Shrock and Wu, 2000; Chang et al., 2007; Teufl and Wagner, 2011; Daouad, 2013; Liang et al., 2014). But most methods proposed require a lot of algebraic calculation. In this research, we propose an efficient combinatorial method based on principle of geometrical transformation (Bipartite and reduction ) to compute the number of spanning trees

Corresponding Author: Noussaima EL Khattabi, Laboratory of Conception and Systems, Faculty of Sciences, Mohammed V University, P.O. Box 1014 RP, Agdal, Rabat, Morocco 
in the small world network $\mathrm{G}_{\mathrm{k}}$ and $\mathrm{C}_{\mathrm{k}}$. Then, we compare the robustness level of $G_{k}$ and $C_{k}$ which have the same average degree of nodes.

\section{MATERIALS AND METHODS}

Methods of decomposition (reduction and bipartite): In this study, we introduce two approaches used in the construction of the small world networks $\mathrm{G}_{\mathrm{k}}$ and $\mathrm{C}_{\mathrm{k}}$, the reduction method and the bipartite method. Reduction and bipartite are tow methods of decomposition based on principle geometrical transformation consist to reduce the number of vertex and edges in a multiple graph $\mathrm{G}$.

Let $\mathrm{G}$ be a planar graph. The reduced graph $\operatorname{Red}_{2}(\mathrm{G})$ is the graph obtained when we add a new edge that connects each two adjacent vertex of G. If we add y-1 edges the obtained graph denoted by $\operatorname{Red}_{y}(\mathrm{G})$, called the y-reduced graph of G (Fig. 1).

Propriety: Let $G$ be a planar graph and $\operatorname{Red}_{y}(G)$ its y-reduced graph, some structural parameters of $\operatorname{Red}_{y}(G)$ depending on the parameters of $\mathrm{G}$ are given by:

- The number of vertex in $\operatorname{Red}_{y}(G)$ is: $\left|V\left(\operatorname{Red}_{y}(G)\right)\right|=\mid V$ (G)|

- The number of edges is: $\left|\mathrm{E}\left(\operatorname{Red}_{\mathrm{y}}(\mathrm{G})\right)\right|=\mathrm{y} \times|\mathrm{E}(\mathrm{G})|$

- The number of faces is: $\left|\mathrm{F}\left(\operatorname{Red}_{\mathrm{y}}(\mathrm{G})\right)\right|=\mid \mathrm{F}$ $(\mathrm{G})|+(\mathrm{y}-1) \times| \mathrm{E}(\mathrm{G}) \mid$

Theorem 1: Let $G$ be a planar graph and $\operatorname{Red}_{y}(G)$ the $y$-reduced graph of $G$. The number of spanning trees in $\operatorname{Red}_{y}(\mathrm{G})$ is given by Lotfi et al. (2015):

$$
\tau\left(\operatorname{Red}_{\mathrm{y}}(\mathrm{G})\right)=\mathrm{y}^{\left|\mathrm{V}_{\mathrm{G}}\right|-1} \times \tau(\mathrm{G})
$$

Let $\mathrm{G}$ be a planar graph. If we add a new vertex in each edge of $G$, the graph obtained $\mathrm{Bip}_{2}(G)$ is The Bipartite graph of $\mathrm{G}$. When we add $\mathrm{x}-1$ new vertex, the obtained graph denoted by $\operatorname{Bip}_{x}(\mathrm{G})$, called the $\mathrm{x}$-Bipartite graph of G (Fig. 2). Now, we give the same structural proprieties for the $\operatorname{Bip}_{x}(\mathrm{G})$.

Propriety 2: Let $G$ be a planar graph and $\operatorname{Bip}_{x}(G)$ its y-reduced graph

- The number of vertex in $\operatorname{Bip}_{\mathrm{z}}(\mathrm{G})$ is: $\left|\mathrm{V}\left(\operatorname{Bip}_{\mathrm{z}}(\mathrm{G})\right)\right|=$ $|\mathrm{V}(\mathrm{G})|+(\mathrm{x}-1) \times|\mathrm{E}(\mathrm{G})|$

- The number of edges is: $\left|\mathrm{E}\left(\operatorname{Bip}_{\mathrm{z}}(\mathrm{G})\right)\right|=\mathrm{x} \times|\mathrm{E}(\mathrm{G})|$

- The number of faces is: $\left|\mathrm{F}\left(\mathrm{Bip}_{\mathrm{z}}(\mathrm{G})\right)\right|=|\mathrm{F}(\mathrm{G})|$

Theorem 2: Let $G$ be a planar graph and $\mathrm{Bip}_{\mathrm{x}}(\mathrm{G})$ the $\mathrm{x}$-Bipartite graph of $\mathrm{G}$. The number of spanning trees in $\mathrm{Bip}_{\mathrm{z}}(\mathrm{G})$ is given by Lotfi et al. (2015):
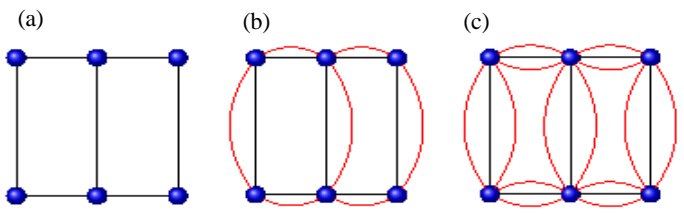

Fig. 1: A graph G, 2-reduced graph and 3-reduced graph: a) $\mathrm{G}$; b) $\operatorname{Red}_{2}(\mathrm{G})$ and c) $\operatorname{Red}_{3}(\mathrm{G})$

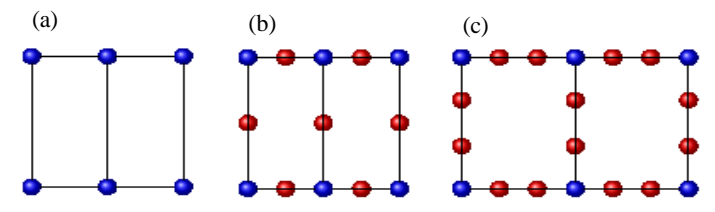

Fig. 2: A graph G, 2-bipartite and 3-bipartite graphs: a) G; b) $\mathrm{Bip}_{2}(\mathrm{G})$ and c) $\mathrm{Bip}_{3}(\mathrm{G})$

$$
\tau\left(\operatorname{Bip}_{\mathrm{z}}(\mathrm{G})\right)=\mathrm{x}^{\left|\mathrm{F}_{\mathrm{G}}\right|-1} \times \tau(\mathrm{G})
$$

The entropy of the small world networks $G_{k}$ and $C_{k}$ : In this study, reduction method and bipartite method are combined in a recursive way to construct the small world networks $G_{k}$ and $C_{k}$ where $G_{k}$ and $C$ are the network formed from $G_{k-1}$ and $C_{k-1}$ the networks of previous iteration $\mathrm{k}-1$, after the reduction transformation and the bipartite transformation. In this research, we study the both cases:

- Reduction transformation followed by bipartite transformation:

$$
G_{\mathrm{n}}^{\mathrm{k}}=\operatorname{Bip}_{\mathrm{x}} \circ \operatorname{Red}_{\mathrm{y}}\left(\mathrm{G}_{\mathrm{k}-1}\right)=\operatorname{Bip}_{\mathrm{z}}\left(\operatorname{Red}_{\mathrm{y}}\left(\mathrm{G}_{\mathrm{k}-1}\right)\right)
$$

- Bipartite transformation followed by reduction transformation:

$$
C_{n}^{k}=\operatorname{Red}_{y} \circ \operatorname{Bip}_{x}\left(C_{k-1}\right)=\operatorname{Red}_{y}\left(\operatorname{Bip}_{x}\left(C_{k-1}\right)\right)
$$

The entropy of $\mathbf{G}_{\mathbf{k}}$ : The construction of the small world networks $G_{k}$ is iterative as follow: $G_{k}=\operatorname{Bip}_{x}{ }^{\circ} \operatorname{Red}_{y}$ $\left(\mathrm{G}_{\mathrm{k}-1}\right)=\operatorname{Bip}_{\mathrm{z}}\left(\operatorname{Red}_{\mathrm{y}}\left(\mathrm{G}_{\mathrm{k}-1}\right)\right)$, the process start with $\mathrm{G}_{0}$ which is simple path contains two vertex, at the next step, the reduced method is applied upon on $\mathrm{G}_{0}$ adding $\mathrm{y}-1$ new edges, followed by the bipartite method adding $\mathrm{x}-1$ vertex in each edge of the network $\operatorname{Red}_{y}\left(G_{0}\right)$. So, the network $G_{1}$ is formed after these geometrical transformations as is illustrated in Fig. 3 where $x=4$ and $y=3 G_{1}=\operatorname{Bip}_{4}{ }^{\circ} \operatorname{Red}_{2}$ $\left(\mathrm{G}_{0}\right)=\operatorname{Bip}_{4}\left(\operatorname{Red}_{2}\left(\mathrm{G}_{0}\right)\right)$. Then, the process go to the next iteration in the same way until the kth iteration. We give the topological proprieties of the network $\mathrm{G}_{\mathrm{k}}$. 

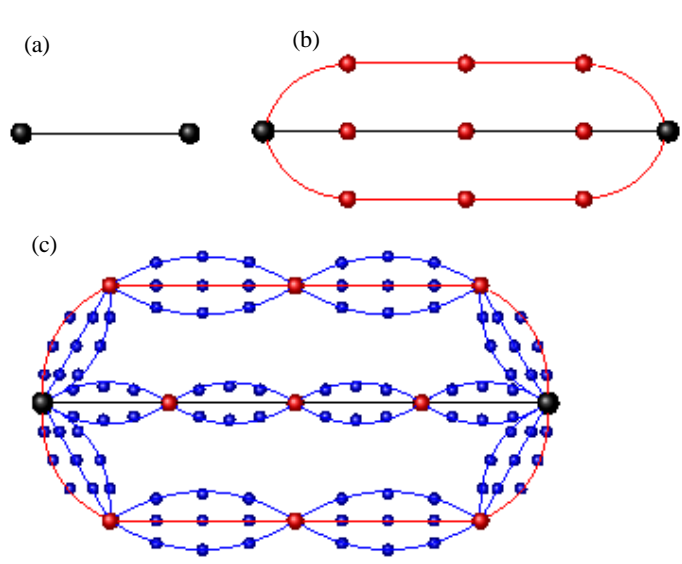

Fig. 3: Networks of the first three iterations of $G_{\mathrm{k}}$ : a) $\mathrm{G}_{0}$; b) $\mathrm{G}_{1}$ and c) $\mathrm{G}_{2}$

Lemma 3.1: $L$ et $G_{k}$ a small world network. The number of vertex, edges and faces are given by:

- $\left|\mathrm{E}\left(\mathrm{G}_{\mathrm{k}}\right)\right|=(\mathrm{xy})^{\mathrm{k}}$

- $\quad \mathrm{V}\left(\mathrm{G}_{\mathrm{k}}\right) \mid=2+\mathrm{y}(\mathrm{x}-1) \frac{(\mathrm{xy})^{\mathrm{k}}-1}{\mathrm{xy}-1}$

- $\left|\mathrm{F}\left(\mathrm{G}_{\mathrm{k}}\right)\right|=1+(\mathrm{y}-1) \frac{(\mathrm{xy})^{\mathrm{k}}-1}{\mathrm{xy}-1}$

Theorem 3.2: The number of spanning trees in the the small world network $G_{\mathrm{k}}$ is given by:

$$
\begin{gathered}
\tau\left(\mathrm{G}_{\mathrm{k}}\right)=\mathrm{x}^{\alpha} \mathrm{y}^{\beta} \\
\alpha=\left(\frac{(\mathrm{y}-1)\left[\mathrm{xy}\left((\mathrm{xy})^{\mathrm{k}}-1\right)-\mathrm{k}(\mathrm{xy}-1)\right]}{(\mathrm{xy}-1)^{2}}\right) \\
\beta=\left(\frac{(\mathrm{x}-1)\left(\mathrm{y}\left((\mathrm{xy})^{\mathrm{k}}-1\right)+\mathrm{k}(\mathrm{y}-1)(\mathrm{xy}-1)\right.}{(\mathrm{xy}-1)^{2}}\right)
\end{gathered}
$$

Proof: According to the construction of $\mathrm{G}_{\mathrm{k}}$ :

$$
\begin{aligned}
& \tau\left(\mathrm{G}_{\mathrm{k}}\right)=\tau\left(\operatorname{Bip}_{\mathrm{x}} \circ \operatorname{Red}_{\mathrm{y}}\left(\mathrm{G}_{\mathrm{k}-1}\right)\right)= \\
& \tau\left(\operatorname{Bip}_{\mathrm{z}}\left(\operatorname{Red}_{\mathrm{y}}\left(\mathrm{G}_{\mathrm{k}-1}\right)\right)\right)
\end{aligned}
$$

by using theorem 1 and 2 , we get:

$$
\begin{aligned}
& \tau\left(\mathrm{G}_{\mathrm{k}}\right)=\mathrm{x}^{\left[\mathrm{f}\left(\operatorname{Red}_{\mathrm{y}}\left(\mathrm{G}_{\mathrm{k}-1}\right) \mid-1\right)\right.} \tau\left(\operatorname{Red}_{\mathrm{y}}\left(\mathrm{G}_{\mathrm{k}-1}\right)\right) \\
& \tau\left(\mathrm{G}_{\mathrm{k}}\right)=\mathrm{x}^{\left(\mid \mathrm{F}\left(\mathrm{Red}_{\mathrm{y}}\left(\mathrm{G}_{\mathrm{k}-1}\right) /-1\right)\right.} \mathrm{y}^{\left(\mid \mathrm{V}\left(\left(\mathrm{G}_{\mathrm{k}-1}\right) \mid-1\right)\right.} \tau\left(\mathrm{G}_{\mathrm{k}-1}\right)
\end{aligned}
$$

by using property 1 , we substitute $\left.\mid \mathrm{F}\left(\operatorname{Red}_{\mathrm{y}}\left(\mathrm{G}_{\mathrm{k}-1}\right)\right)\right) \mid$ by its value we obtain:

$$
\begin{aligned}
& \tau\left(\mathrm{G}_{\mathrm{k}}\right)=\mathrm{x}^{\left(\mathrm{F}\left(\mathrm{G}_{\mathrm{k}-1}\right)|+(\mathrm{G}-1)| \mathrm{E}\left(\mathrm{G}_{\mathrm{k}-1}\right) \mid-1\right)} \mathrm{y}^{\left(\mathrm{W}\left(\left(\mathrm{G}_{\mathrm{k}-1}\right) \mid-1\right)\right.} \tau\left(\mathrm{G}_{\mathrm{k}-1}\right) \\
& \tau\left(\mathrm{G}_{\mathrm{k}-1}\right)=\mathrm{x}^{\left(\left|\mathrm{F}\left(\mathrm{G}_{\mathrm{k}-2}\right)\right|+(\mathrm{G}-1)\left|\mathrm{E}\left(\mathrm{G}_{\mathrm{k}-2}\right)\right|-1\right)} \mathrm{y}^{\left(\mid \mathrm{V}\left(\left(\mathrm{G}_{\mathrm{k}-2}\right) \mid-1\right)\right.} \tau\left(\mathrm{G}_{\mathrm{k}-2}\right) \\
& \tau\left(\mathrm{G}_{1}\right)=\mathrm{x}^{\left.\left(\mathbb{F}\left(\mathrm{G}_{0}\right)|+(\mathrm{g}-1)|\right)\left|\left(\mathrm{G}_{0}\right)\right|-1\right)} \mathrm{y}^{\left(\left|\mathrm{V}\left(\mathrm{G}_{0}\right)\right|-1\right)} \tau\left(\mathrm{G}_{0}\right)
\end{aligned}
$$

where, $\tau\left(\mathrm{G}_{0}\right)=1$. We multiply these equations, then, we get:

$$
\tau\left(\mathrm{G}_{\mathrm{k}}\right)=\mathrm{x}^{\left.\sum_{\mathrm{i}=0}^{k-1}\left(\mathbb{F}\left(\mathrm{G}_{\mathrm{i}}\right) \mid+(\mathrm{y}-1)\right) \mathbb{E}\left(\mathrm{G}_{\mathrm{i}}\right) \mid-1\right)} \mathrm{y}^{\sum_{\mathrm{i}=0}^{k-1}\left(\mathbb{V}\left(\mathrm{G}_{\mathrm{i}}\right) \mid-1\right)}
$$

using lemma 3.1 to substitute $|\mathrm{V}(\mathrm{G})|,\left|\mathrm{F}\left(\mathrm{G}_{\mathrm{i}}\right)\right|$ and $\left|\mathrm{E}\left(\mathrm{G}_{\mathrm{i}}\right)\right|$ :

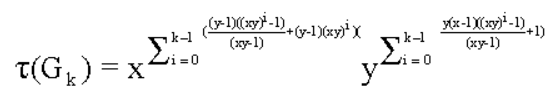

we calculate the both summation, then, we get the result.

Corollary 3.3: Let $G_{k}$ be a small world network, the asymptotic spanning tree entropy of $\mathrm{G}_{\mathrm{k}}$ given by:

$$
\rho\left(\mathrm{G}_{\mathrm{k}}\right)=\frac{(\mathrm{y}-1) \mathrm{x} \log (\mathrm{x})+(\mathrm{x}-1) \log (\mathrm{y})}{(\mathrm{x}-1)(\mathrm{xy}-1)}
$$

Proof: As is already defined, the asymptotic entropy of $G_{k}$ is a the limiting value:

$$
\rho\left(G_{\mathrm{k}}\right)=\lim _{\left|\mathrm{G}_{\mathrm{k}}\right| \rightarrow+\infty} \frac{\log \tau\left(\mathrm{G}_{\mathrm{k}}\right)}{\left|\mathrm{G}_{\mathrm{k}}\right|}
$$

Using the above theorem and substituting $\tau\left(G_{k}\right)$ by its expression where:

$$
\left|\mathrm{V}\left(\mathrm{G}_{\mathrm{k}}\right)\right|=2+\mathrm{y}(\mathrm{x}-1) \frac{(\mathrm{xy})^{\mathrm{k}}-1}{\mathrm{xy}-1}
$$

We get:

$$
\begin{aligned}
& \rho\left(G_{k}\right)=\lim _{\left|G_{k}\right| \rightarrow+\infty} \frac{\log \left(\tau\left(G_{k}\right)\right)}{\left|G_{k}\right|}
\end{aligned}
$$

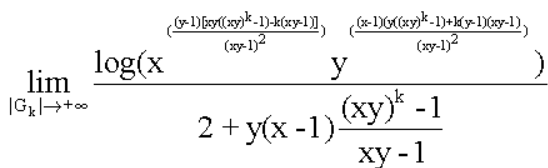

$$
\begin{aligned}
& =\frac{(\mathrm{y}-1) \mathrm{x} \log (\mathrm{x})+(\mathrm{x}-1) \log (\mathrm{y})}{(\mathrm{xy}-1)(\mathrm{x}-1)}
\end{aligned}
$$

Hence, the result.

The entropy of $\mathbf{C}_{\mathbf{k}}$ : The construction of the small world networks $C_{k}$ is similar to the construction of $G_{k}$ it is as follow:

$$
C_{k}=\operatorname{Red}_{y} \circ \operatorname{Bip}_{z}\left(C_{k-1}\right)=\operatorname{Red}_{y}\left(\operatorname{Bip}_{x}\left(C_{k-1}\right)\right)
$$




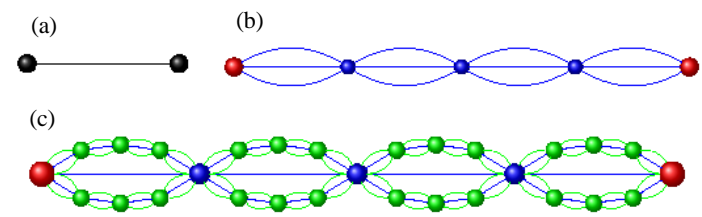

Fig. 4: Networks of the first three iteration of $\mathrm{C}_{\mathrm{k}}$; a) $\mathrm{C}_{0}$; b) $\mathrm{C}_{1}$ and c) $\mathrm{C}_{2}$

At the first iteration, we apply the bipartite method by adding new $x-1$ vertex to $C_{0}$, then, we apply the reduced method, adding $\mathrm{y}-1$ new edges between each two adjacent vertex in the network $\mathrm{Bib}_{\mathrm{z}}\left(\mathrm{C}_{0}\right)$. So, the network $\mathrm{C}_{1}$ is built after these geometrical transformations (Fig. 4) with $\mathrm{x}=4$ and $\mathrm{y}=2\left(\mathrm{C}_{1}=\operatorname{Red}_{2} \circ \mathrm{Bip}_{4}\left(\mathrm{C}_{0}\right)\right)$. Then with the same manner, the process is repeated in the next iteration until the kth iteration.

Lemma 4.1: Let $C_{k}$ a small world network. The structural proprieties of the network $\mathrm{C}_{\mathrm{k}}$ are given by:

- The number of vertex: $\left|\mathrm{E}\left(\mathrm{C}_{\mathrm{k}}\right)\right|=(\mathrm{xy})^{\mathrm{k}}$

- The number of edges $\left|\mathrm{V}\left(\mathrm{C}_{\mathrm{k}}\right)\right|=2+(\mathrm{x}-1)(\mathrm{xy})^{\mathrm{k}}{ }_{1} / \mathrm{xy}-1$

- The number of faces $\left|\mathrm{F}\left(\mathrm{C}_{\mathrm{k}}\right)\right|=1+\mathrm{x}(\mathrm{y}-1)(\mathrm{xy})^{\mathrm{k}}{ }_{1} / \mathrm{xy}-1$

Theorem 4.2: The number of spanning trees in the the small world network $\mathrm{C}_{\mathrm{k}}$ is given by:

$$
\begin{gathered}
\tau\left(C_{k}\right)=y^{\lambda} x^{\mu} \\
\lambda=\frac{(x-1) x y\left((x y)^{k}-1\right)+k x(y-1)(x y-1)}{(x y-1)^{2}} \\
\mu=\frac{x(y-1)\left[\left((x y)^{k}-1\right)-k(x y-1)\right]}{(x y-1)^{2}}
\end{gathered}
$$

Proof: According to the construction of $\mathrm{C}_{\mathrm{k}}$ :

$$
\tau\left(C_{k}\right)=\tau\left(\operatorname{Red}_{y} \circ \operatorname{Bip}_{z}\left(C_{k-1}\right)\right)=\tau\left(\operatorname{Red}_{y}\left(\operatorname{Bip}_{z}\left(C_{k-1}\right)\right)\right)
$$

By using theorem 1 and 2, we get:

$$
\begin{gathered}
\tau\left(\mathrm{C}_{\mathrm{k}}\right)=\mathrm{y}^{\left(\mathrm{VBip} \mathrm{p}_{\mathrm{x}}\left(\mathrm{C}_{\mathrm{k}-1}\right) \mid-1\right)} \tau\left(\operatorname{Bip}_{\mathrm{z}}\left(\mathrm{C}_{\mathrm{k}-1}\right)\right) \\
\tau\left(\mathrm{C}_{\mathrm{k}}\right)=\mathrm{y}^{\left(\left(\mathrm{VBip} \mathrm{p}_{\mathrm{x}}\left(\mathrm{C}_{\mathrm{k}-1}\right) \mid-1\right)\right.} \mathrm{x}^{\left(\left|\mathrm{F}\left(\mathrm{C}_{\mathrm{k}-1}\right)\right|-1\right)} \tau\left(\mathrm{C}_{\mathrm{k}-1}\right)
\end{gathered}
$$

By using property 2, we substitute $\left.\mid \mathrm{V}\left(\operatorname{Bip}_{\mathrm{z}}\left(\mathrm{C}_{\mathrm{k}-1}\right)\right)\right) \mid$ by its value we obtain:

$$
\tau\left(C_{k}\right)=y^{\left(\left|V\left(C_{k-1}\right)\right|+(x-1) \mid\left[\left(C_{k-1}\right) \mid-1\right)\right.} x^{\left(\mid F\left(\left(C_{k-1}\right) \mid-1\right)\right.} \tau\left(C_{k-1}\right)
$$

$$
\begin{aligned}
& \tau\left(\mathrm{C}_{\mathrm{k}-1}\right)=\mathrm{y}^{\left(\left|\mathrm{V}\left(\mathrm{C}_{\mathrm{k}-2}\right)\right|+(\mathrm{z}-1)\right) \mid\left[\left(\mathrm{C}_{\mathrm{k}-2}\right) \mid-1\right)} \mathrm{x}^{\left(\mathbb{F}\left(\left(\mathrm{C}_{\mathrm{k}-2}\right) \mid-1\right)\right.} \tau\left(\mathrm{C}_{\mathrm{k}-2}\right) \\
& \mathrm{t}\left(\mathrm{C}_{1}\right)=\mathrm{y}^{\left.\left(\mathrm{VV}\left(\mathrm{C}_{0}\right) \mid+(\mathrm{z}-1)\right) \mathbb{E}\left(\mathrm{C}_{0}\right) \mid-1\right)} \mathrm{x}^{\left.\left(\mid \mathrm{F}\left(\mathrm{C}_{0}\right)\right)-1\right)} \tau\left(\mathrm{C}_{0}\right)
\end{aligned}
$$

where $\tau\left(\mathrm{C}_{0}\right)=1$. We multiply these equations, then we get:

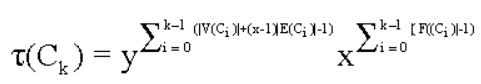

using lemma 4.1 to substitute $\left|\mathrm{V}\left(\mathrm{G}_{\mathrm{i}}\right)\right|,\left|\mathrm{F}\left(\mathrm{G}_{\mathrm{i}}\right)\right|$ and $\left|\mathrm{E}\left(\mathrm{G}_{\mathrm{i}}\right)\right|$ :

$$
\tau\left(C_{k}\right)=y^{\sum_{i=0}^{k-1}\left(\frac{(x-1)\left((x y)^{i}-1\right)}{(x y-1)}+(x-1)(z y)^{i}\right)} x^{\left.\sum_{i=0}^{k-1} \frac{z(y-1)\left((x y-)^{i}-1\right)}{(x y-1)}\right)}
$$

we calculate these summation, then, we get the result.

Corollary 4.3: Let $C_{k}$ be a small world network, the asymptotic spanning tree entropy of $\mathrm{G}_{\mathrm{k}}$ given by:

$$
\rho\left(C_{k}\right)=\frac{x y(x-1) \log (x)+x(y-1) \log (y)}{(x-1)(x y-1)}
$$

Proof: As is already defined, the asymptotic entropy of $C_{k}$ is:

$$
\rho\left(\mathrm{C}_{\mathrm{K}}\right)=\lim _{\left|\mathrm{C}_{\mathrm{k}}\right| \rightarrow+\infty} \frac{\log \tau\left(\mathrm{C}_{\mathrm{k}}\right)}{\left|\mathrm{C}_{\mathrm{k}}\right|}
$$

Using the above theorem and substituting $\left(\mathrm{C}_{\mathrm{k}}\right)$ by its expression where:

$$
\mathrm{V}\left(\mathrm{C}_{\mathrm{k}}\right) \mid=2+(\mathrm{x}-1) \frac{(\mathrm{xy})^{\mathrm{k}}-1}{\mathrm{xy}-1}
$$

we get:

$$
\rho\left(C_{k}\right)=\lim _{\left|C_{k}\right| \rightarrow+\infty} \frac{\log \tau\left(C_{k}\right)}{\left|C_{k}\right|}
$$

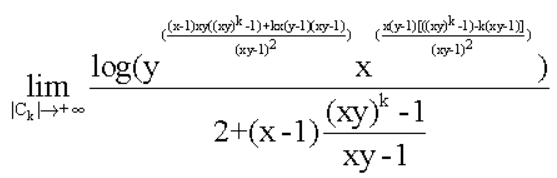

$$
=\frac{x y(x-1) \log x+x(y-1) \log y}{(x-1)(x y-1)}
$$

\section{RESULTS AND DISCUSSION}

Results interpretation: Now we compare the asymptotic entropy of the two complex networks $G_{k}$ and $C_{k}$ which have the same average degree. First we give some particular values for $\mathrm{x}$ and $\mathrm{y}$, for example, we choose $\mathrm{x}=4$, we get curves of $\rho\left(C_{k}\right)$ and $\rho\left(G_{k}\right)$ depending on $y$. And we give $y=3$, we get curves of $\rho\left(C_{k}\right)$ and $\rho\left(G_{k}\right)$ depending on x. Next, we plot $\rho\left(C_{k}\right)$ and $\rho\left(G_{k}\right)$ as multiple variables 

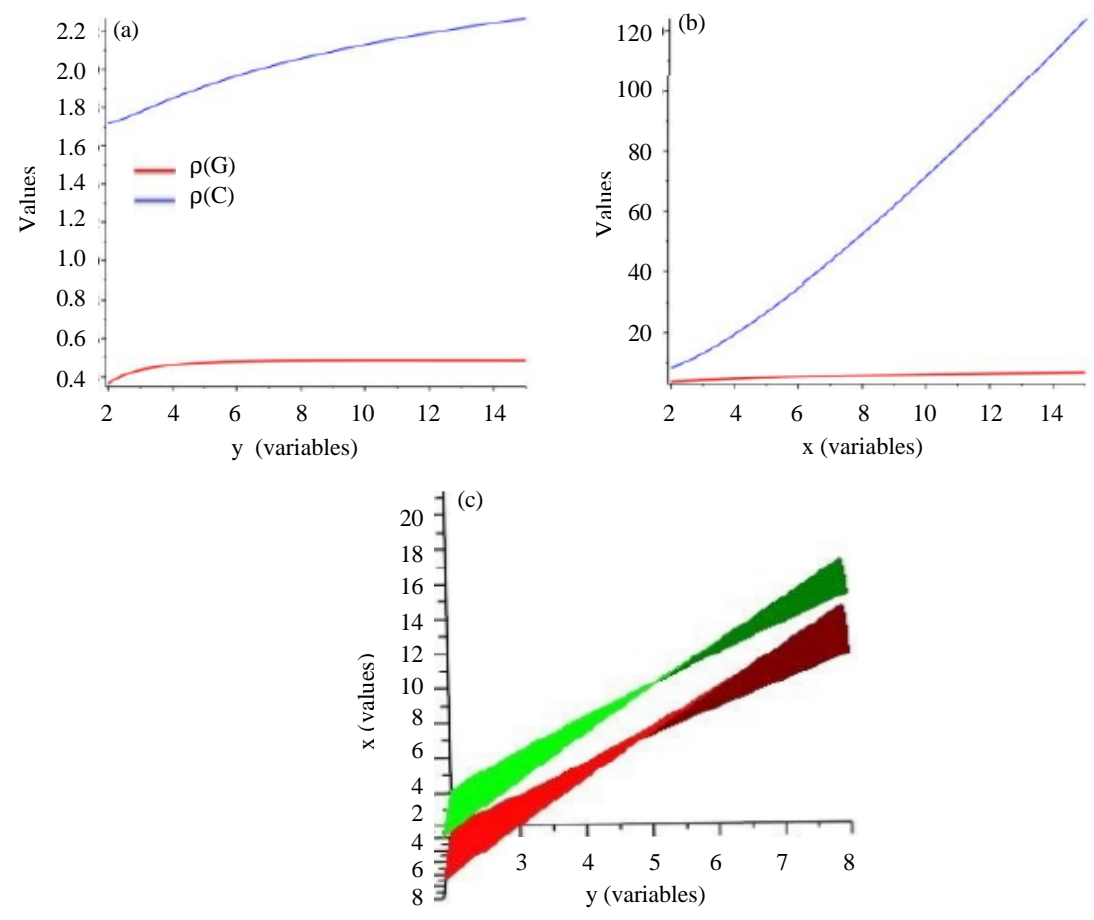

Fig. 5: Multiple variables functions: a) The curves are ploted with $x=4 ; b$ ) The curves are ploted with $x=3$ and c) The curve $\operatorname{pf} \rho(\mathrm{G})$ is red and $\rho(\mathrm{C})$ is green

functions that depend on $\mathrm{x}$ and $\mathrm{y}$. All obtained Fig. 5 show clearly $\rho\left(\mathrm{C}_{\mathrm{k}}\right)$ is higher than $\rho\left(\mathrm{G}_{\mathrm{k}}\right)$. Indeed, algebraically we prove $\rho\left(C_{k}\right)$ is higher than $\rho\left(G_{k}\right)$ :

$$
\begin{aligned}
& \rho\left(C_{k}\right)-\rho\left(G_{k}\right)=\frac{x y(x-1) \log x+x(y-1) \log y}{(x-1)(x y-1)} \\
& -\frac{(y-1) x \log x+(x-1) \log y}{(x-1)(x y-1)} \\
& v\left(C_{k}\right)-\rho\left(G_{k}\right)=\frac{x(y x-2 y+1) \log (x)+(x y-2 x+1) \log (y)}{(x-1)(x y-1)}
\end{aligned}
$$

$(x \geq 2)$ and $(y \geq 2) \Rightarrow\left(C_{k}\right)-\rho\left(G_{k}\right) \geq 0$. It means the network $\mathrm{C}_{\mathrm{k}}$ has more spanning trees than the other network $\mathrm{G}_{\cdot k}$ Thus, This result proves the network $\mathrm{C}_{\mathrm{k}}$ is more robust and more reliable than the network $G_{k}$. Then, owing to the growth of the number of spanning trees in $\mathrm{C}_{\mathrm{k}}$ which provides more connection between nodes related by eventual interrupted links that ensures more reliability and robustness and avoid having dysfunction of this network.

\section{CONCLUSION}

The asymptotic spanning tree entropy of a network is used to measure reliability and robustness of network. In this study, We proposed two combinatorial approaches: the bipartite and the reduction to construct two examples of small world network by giving their topological properties, computing their number of spanning trees. Finally, we evaluated their spanning tree entropy in order to estimate and compare the level of robustness of these two type of complex network that have the same average degree.

\section{REFERENCES}

Cancho, R.F.I., C. Janssen and R.V. Sole, 2001. Topology of technology graphs: Small world patterns in electronic circuits. Phys. Rev. E., 64: 046119-1-046119-5.

Chang, S.C., L.C. Chen and W.S. Yang, 2007. Spanning trees on the Sierpinski gasket. J. Stat. Phys., 126: 649-667.

Colbourn, C.J., 1987. The Combinatorics of Network Reliability. Oxford University Press, Oxford, UK., ISBN:9780195049206, Pages: 160.

Daouad, S.N., 2013. Number of spanning trees of corona of some special graphs. Bull. Math. Sci. Appl., 1: $40-48$.

Javari, A., M. Izadi and M. Jalili, 2016. Recommender Systems for Social Networks Analysis and Mining: Precision Versus Diversity. In: Complex Systems and Networks, Lu, J., X. Yu, G. Chen and W. Yu (Eds.). Springer, Berlin, Germany, ISBN:9783662478233, pp: 423-438. 
Kirkhoff, G., 1847. [On the resolution of the equations, which are called for when investigating the linear distribution of galvanic currents (German)]. Ann. Phys. Chem., 148: 497-508.

Liang, D., F. Li and Z. Xu, 2014. The number of spanning trees in a new lexicographic product of graphs. Sci. China Inf. Sci., 57: 1-9.

Lotfi, D., M.E. Marraki and D. Aboutajdine, 2015. The enumeration of spanning trees in dual, bipartite and reduced graphs. J. Discrete Math. Sci. Cryptography, 18: 673-687.

Lyons, R., 2005. Asymptotic enumeration of spanning trees. Combin. Probab. Comput., 14: 491-522.

Myrvold, W., K.H. Cheung, L.B. Page and J.E. Perry, 1991. Uniformly-most reliable networks do not always exist. Networks Intl. J., 21: 417-419.

Newman, M., A.L. Barabasi and D.J. Watts, 2006. The Structure and Dynamics of Networks. Princeton University Press, Princeton, New Jersey, USA., ISBN-13:978-0-691-11356-2, Pages: 575.

Newman, M.E.J., 2003. The structure and function of complex networks. Soc. Ind. Applied Math. Rev., 45: 167-256.
Nikolopoulos, S.D. and C. Papadopoulos, 2004. The number of spanning trees in $\mathrm{K}_{\mathrm{n}}$-complements of quasi-threshold graphs. Graphs Comb., 20: 383-397.

Nishikawa, T. and A.E. Motter, 2006. Synchronization is optimal in nondiagonalizable networks. Phys. Rev. E, Vol. 73. 10.1103/PhysRevE. 73.065106

Reggiani, A., P. Nijkamp and A. Cento, 2010. Connectivity and concentration in airline networks: A complexity analysis of lufthansas network. Eur. J. Inf. Syst., 19: 449-461.

Shrock, R. and F.Y. Wu, 2000. Spanning trees on graphs and lattices in d dimensions. J. Phys. A: Math. Gen., 33: 881-3902.

Teufl, E. and S. Wagner, 2011. Resistance scaling and the number of spanning trees in self-similar lattices. J. Stat. Phys., 142: 879-897.

Wang, B., H. Tang, C. Guo and Z. Xiu, 2006. Entropy optimization of scale-free networks robustness to random failures. Phys. A. Stat. Mech. Appl., 363: 591-596.

Wu, F.Y., 1977. Number of spanning trees on a lattice. J. Phys. A. Math. Gen., 10: L113-L115.

Zhang, S., 2015. Network analysis, integration and methods in computational biology: A brief survey on recent advances. Complex Syst. Networks, 1: 459-482. 